\title{
Review of: "The association of smoking status with SARS- CoV-2 infection, hospitalisation and mortality from COVID-19: A living rapid evidence review with Bayesian meta-analyses (version 7)"
}

\author{
Peter Hajek ${ }^{1}$ \\ 1 Queen Mary, University of London \\ Potential competing interests: The author(s) declared that no potential competing interests exist.
}

This is proving a very useful living review, well done!

Here are two minor comments.

To the list of issues complicating interpretation, you may consider adding that early on, a non-negligible proportion of infections was acquired in hospitals, by people admitted with other illnesses. Smokers and ex-smokers are likely to be over-represented among this group; and this group was also likely to have more severe outcomes.

Regarding the interpretation of a possible protective effect of smoking, should such a thing exist, only the role of nicotine is considered. Inhaling hot smoke regularly throughout the day is another candidate mechanism. E.g. heat and inhaling humidified hot air seem to inhibit early replication of rhinoviruses https:/www.ncbi.nlm.nih.gov/pmc/articles/PMC1836535/ https://www.ncbi.nlm.nih.gov/pmc/articles/PMC89212/ 